\title{
MONETARY POLICY RULES AND MACROECONOMIC STABILITY: EVIDENCE FROM SRI LANKA
}

\author{
Kesavarajah Mayandy \\ Senior Economist, Central Bank of Sri Lanka, Sri Lanka. Email: kesavan@cbsl.lk
}

\begin{abstract}
This study estimates the forward-looking monetary policy reaction function for Sri Lanka using monthly data from 1980 to 2017. The results indicate that the Central Bank of Sri Lanka (CBSL) followed the Taylor rule to set interest rates. Our forwardlooking model estimations show that the coefficient on inflation increases over time, reflecting the greater focus on price stability by the bank. The results suggest that the CBSL reacted to nominal exchange rate depreciation by tightening monetary policy. Although the degree of interest rate smoothness gradually decreases over time, the study shows that the CBSL did not react to movements in fiscal deficit during the period under investigation. This finding suggests that the inclusion of fiscal deficit in the Taylor rule does not provide a better specification of the policy reaction function in Sri Lanka.
\end{abstract}

Keywords: Monetary policy; Taylor rule; Central Bank of Sri Lanka.

JEL Classifications: E43; E52; E58.

Article history:

Received : November 01, 2019

Revised : November 03, 2019

Accepted : : December 28, 2019

Available online : December 31, 2019

https://doi.org/10.21098/bemp.v22i4.1191 


\section{INTRODUCTION}

The Taylor (1993) rule, which defines monetary policy based on the deviations of output and inflation from their respective targets, is a popular benchmark for assessing the monetary policy stance of central banks (Orphanides, 2001; Taylor and Williams, 2010). Several economists argue that central banks should follow a simple policy instrument rule whose execution will have a significant impact on economic performance (Bernanke, 2010; Taylor, 2013). A flexible exchange rate in conjunction with a simple monetary policy rule based on inflation targeting is the only sound monetary policy available for developing and emerging economies (Taylor, 2000). However, numerous studies have criticized the Taylor rule on the grounds of its lack of practical applicability (McCallum and Nelson, 1999; Svensson, 2003; Martin and Milas, 2013; Ghosh et al., 2016). In the aftermath of the financial crisis of 2007-2008, several major economies faced prolonged periods of low nominal interest rates and even faced a zero lower bound. This led major central banks to adopt nonstandard measures (Jung, 2018), and the policy rates of several central banks were subject to great deviations. The policy rates of major central banks have thus been typically below the levels implied by the Taylor rule, and the deviations of policy interest rates from the levels implied by the Taylor rule have increased, especially since the early 2000s. Taylor (2013) argues that deviations from the Taylor rule could be due to international spillovers. The rule could thus still be sound, since a central bank can still pursue other measures to ease its monetary policy stance, even when the economy experiences a zero lower bound.

However, in the recent years, several studies have reinvestigated the practical applicability of the original Taylor rule while incorporating theoretically important variables that central banks should consider to enhance the stabilization role of monetary policy (Reinhart and Rogoff, 2009; Taylor and Williams, 2010; Sargent, 2014). ${ }^{1}$ In addition to output and inflation, these studies have highlighted that the policy response of central banks should focus on variables such as asset prices, fiscal deficit, exchange rates, commodity prices, and other business cycle variables (Chuku and Middleditch, 2016). Studies, such as those of Gray (2012) and Taylor (2013), have shown that the specification of the Taylor rule can be enhanced through the addition of the spillover of central bank decisions in other countries. At the current stage, however, it appears that central banks are using the simple monetary policy rule as a reference guide rather following a specific fixed rule (Jung, 2018).

Over the past three decades, although the Sri Lankan economy has registered high levels of growth and low levels of inflation, both inflation and growth have been highly volatile, with a notable and regular cyclical behavior. The variability of inflation has dropped noticeably, whereas that of output has increased significantly. The economy has experienced a transition from regimes of relatively low volatility to more volatile regimes. In this context, the present study examines whether the monetary policy reaction function in Sri Lanka is associated with appropriate policy settings, as suggested by the Taylor rule, based on implications of the Taylor principle. We investigate the Taylor principle empirically within

1 Clarida et al. (1998, 2000), Woodford (2001), Svensson (2003), Martin and Milas (2013), and Caglayan et al. (2016) also investigate the original Taylor rule. 
the framework of the augmented Taylor rule. Since a lack of fiscal discipline is incompatible with the goal of price stability, fiscal variables are considered to play an important role in the monetary policy strategy of many developing economies (Allard, Catenaro, Vidal, and Wolswijk, 2013). Sri Lanka is no exception in this regard. Since Sri Lanka encounters fiscal constraints over the period of study, we include fiscal deficit in the augmented Taylor rule. This allows us to capture the role of fiscal policy in explaining the dynamic behavior of the nominal interest rate in Sri Lanka (Bodea and Higashijima, 2017). In this context, the present study offers new empirical evidence on the role of fiscal deficit in the policy reaction function of the Central Bank of Sri Lanka (CBSL). The study's entire sample period is divided into three subperiods, based on structural changes that have taken place in the Sri Lankan economy.

The main results of this study can be summarized as follows. First, from the estimated forward-looking open economy Taylor rule, we find that the Taylor principle does not hold for the full-sample period. However, the subsample analysis carried out across different policy regimes confirms satisfaction of the Taylor principle in all periods, except from 1980 to 2000. Second, we find that Sri Lankan policymakers reacted to nominal exchange rate depreciation by tightening monetary policy. The study also finds that the degree of interest rate smoothness has gradually decreased over time. Meanwhile, the size of the coefficient on inflation is found to increase over time, reflecting greater focus on price stability. Finally, this study provides evidence that the monetary authority in Sri Lanka did not react to movements in fiscal deficit during the period under investigation. This finding suggests that the inclusion of fiscal deficit in the Taylor rule does not provide a better specification of the policy reaction function in Sri Lanka. The present study provides empirical support for those studies that estimate forwardlooking policy reaction functions. Additionally, this study offers new empirical evidence with respect to the role of fiscal deficit in the policy reaction function of the CBSL.

The remainder of the paper is organized as follows. Section II reviews the literature on the Taylor rule. Section III outlines the data and methodological framework. Section IV provides quantitative insights on the monetary policy reaction function in Sri Lanka. Finally, Section V summarizes the study's major findings.

\section{LITERATURE REVIEW}

The standard Taylor rule, which follows the seminal contribution of Taylor (1993), is increasingly used in empirical research on monetary policy and is written as follows:

$$
i_{t}=\bar{r}+\beta_{\pi}\left(\pi_{t}-\pi^{*}\right)+\beta_{y}\left(y_{t}-y_{t}^{*}\right)+\pi^{*}
$$

where $i_{t}$ is the policy interest rate, $\bar{r}$ is the equilibrium real interest rate, $\pi_{t}$ is the inflation rate, $\pi^{*}$ is the targeted inflation rate, and $\left(y_{t}-y_{t}^{*}\right)$ denotes the output gap. In Taylor's (1993) study of the Federal Reserve System's monetary policy from 1987 
to 1992, a value of 0.5 is assigned to both $\beta_{\pi}$ and $\beta_{y}$. Further, Taylor assigns a value of two to $\bar{r}$. Since the Federal Reserve was targeting an inflation rate of $2 \%$ when both inflation and output were at their respective target levels, the "equilibrium" federal funds rate is equal to four.

The Taylor principle consist of four elements. The first states that the coefficient on inflation should be significant and greater than one. Accordingly, monetary policy should respond to increases in inflation with more than a one-to-one increase in the nominal interest rate in order for the real interest rate to increase (Woodford, 2001, 2007; Nikolsko-Rzhevskyy et al., 2015). Hence, theoretical studies on the stabilizing properties of Taylor-type rules reveal the importance of implementing a so-called active monetary policy. ${ }^{2}$ The second element of the principle states that the coefficient of the output gap should be significant and greater than zero but less than one. Satisfying these two components of the principle helps to stabilize business cycle fluctuations (Ince, Molodtsova, and Papell, 2016). Accordingly, the central bank will reduce its policy rates when inflation, the output gap, or both decline. The third element of the principle states that the target inflation rate $^{3}$ should equal $2.0 \%$. The last component of the principle states that the equilibrium real interest rate should be constant and equal to $2.0 \%$. Although it is possible to estimate both inflation targets and equilibrium real interest rates, the criteria for satisfying the last two principle elements do not have an exact statistical interpretation. Therefore, most studies on the Taylor rule typically focus on the first element of the principal. This study will follow a similar approach.

Several studies have estimated the policy reaction functions of the central banks in both developing and advanced economies. However, recent studies have shown that the reaction functions of the central banks are often confronted with issues of nonlinearity, structural breaks, and time-varying behavior (Chuku and Middleditch, 2016). A recent study by Jung (2018), who investigates the monetary policy stance of the European Central Bank during the 2008 global financial crisis, shows that both the Taylor rule and the McCallum rule (2000) are closely related in terms of explaining the European Central Bank's monetary policy stance. The author finds that the interest rates derived using both rules are close to the actual policy rates for most of the period considered. However, the study finds no evidence to support the superiority of McCallum's (2000) rule compared to Taylor's rule, especially when interest rates are very low.

Miles and Schreyer (2012) examine the reaction functions of the central banks of four Asian countries, namely, Thailand, Malaysia, Korea, and Indonesia, using quantile regression analysis. Their results present evidence of nonlinearities in the reaction functions, but with cross-country differences. For instance, the monetary authorities in Indonesia do not respond to the output gap in the lower quantiles, whereas the central bank of Korea responds to the output gap in both quantiles. However, among the four countries, only the central banks of Malaysia and Indonesia react to exchange rate fluctuations. A recent study by Jawadi, Mallick, and Sousa (2014), using a smooth transition regression model, shows that central

2 An active monetary policy rule is one in which the monetary authority satisfies the Taylor principle, in that they adjust the nominal interest rate such that the real interest rate rises in response to excess inflation. Conversely, a passive monetary rule is one that fails to satisfy this principle.

3 The inflation target is adopted either implicitly or explicitly by many central banks in both developed and developing economies. 
banks in China and Brazil significantly react to changes in the real effective exchange rate. Shrestha and Semmler (2015) estimate a simple Taylor rule for five East Asian countries, namely, Korea, Malaysia, Thailand, the Philippines, and Indonesia. They argue that the baseline Taylor rule is not sufficient to describe monetary policy in emerging countries and suggest that the policy rule of the central bank should also include financial conditions. Clarida, Gali, and Gertler (1998) investigate the empirical validity of the Taylor rule in two sets of countries, the G3 (Germany, Japan, and the United States) and the E3 (the United Kingdom, France, and Italy). Their results show that the monetary authorities in G3 countries adjusted the real interest rate in response to inflationary pressures, following a forward-looking rather than a backward-looking monetary policy rule. However, the study reveals that France and Italy follow very closely the interest rate set by the Deutsche Bundesbank.

A recent study by Chuku and Middleditch (2016) shows that the monetary and fiscal authorities in economies with high levels of resource exports respond to commodity price slack, but in different ways, depending on the policy regime in place. This literature argues that monetary authorities in primary commodity export economies often do not react aggressively enough to achieve their announced inflation targets. Similarly, using a dynamic stochastic general equilibrium model of a small open economy, Kumhof, Nunes, and Yakadina (2010), for example, examine whether a central bank can follow an inflation target under fiscal dominance. Their results suggest that it is impractical and undesirable for central banks to satisfy the Taylor principle when an economy experiences fiscal dominance. In particular, Kumhof et al. show that, under fiscal dominance, an interest rate rule that includes public debt would result in high inflation volatility. The authors further show that welfare gains generated through the reaction of fiscal variables are negligible compared to the gains derived from the elimination of fiscal dominance. Therefore, the literature argues that fiscal reform is crucial before an inflation-targeting framework can be implemented by central banks in either developing or advanced economies.

Clarita, Gali, and Gertler (2000) estimate the forward-looking monetary policy reaction functions of the United States from 1960 to 1996. Based on the estimated reaction functions across periods, they find substantial differences in the way monetary policy was conducted during the period investigated: from 1960 to 1979,4 the Fed typically raised its policy rates by less than any increase in expected inflation, thus allowing real short-term interest rates to decline as expected inflation increased. Conversely, from 1979 to 1996, the Fed raised the real as well as nominal short-term interest rates in response to higher expected inflation. These results show that the interest rate policy after 1979 was much more sensitive to changes in expected inflation compared to before.

In the case of Sri Lanka, Perera and Jayawickrema (2013) estimate alternative monetary policy reaction functions using the standard linear Taylor rule. Using quarterly data for the period from 1996 to 2013, they find that the size of the coefficient on the inflation gap increases over time, reflecting greater focus on

\footnotetext{
4 The period from 1960 to 1979 corresponds to the tenures of William M. Martin, Arthur Burns, and G. William Miller as Federal Reserve chair, while the second period, from 1979 to 1996, encompasses the tenures of Paul Volcker and Alan Greenspan as Fed chair.
} 
price stability. However, their results suggest that the responses to fluctuations in output gap were greater than the deviations in inflation. Meanwhile, using an open economy New Keynesian dynamic stochastic general equilibrium model, Ehelepola (2015) estimates the welfare-maximizing optimal monetary policy rules for Sri Lanka. The author finds that policymakers responded more aggressively to inflation but had only a moderate response to the output gap. Ehelepola shows that policymakers also reacted to exchange rate fluctuations.

\section{DATA AND METHODOLOGY}

A. Data

This study uses monthly time series data for the period from January 1980 to December 2017; see Appendix Figure 1A for a plot of the data. The study begins in 1980 to coincide with the adoption of the monetary targeting a policy framework in Sri Lanka. The data on the exchange rates, interest rates, and fiscal variables are mainly drawn from annual reports of the CBSL. The data for other variables were extracted from three different sources. The growth rates of the real gross domestic production (GDP) and inflation rates are mainly based on various publications of the Department of Census and Statistics of Sri Lanka. Since the monthly real GDP series are not available for Sri Lanka, we use the cubic spline interpolation technique proposed by Fox (2000) to convert the available data to a monthly series. Due to the unavailability of monthly time series data on the policy rates of the CBSL, we consider the three-month Treasury bill rate to be the short-term interest rate. The output gap is calculated as the percentage deviation of the real GDP from its trend value obtained by the Hodrick-Prescott filter. Although the HodrickPrescott filter has shortcomings, we use it because of its flexibility in tracking trend output (Konuki, 2010). A detailed description of the data series and their sources is given in the Appendix Table A1. The Appendix Tables A2 and A3 also include the descriptive statistics and correlation matrix of the variables.

Figure 1.

Movements of the Inflation and Output Growth in Levels

This figure plots two series - the inflation rate and the economic growth rate. The time-series data are from 1980 to 2017.

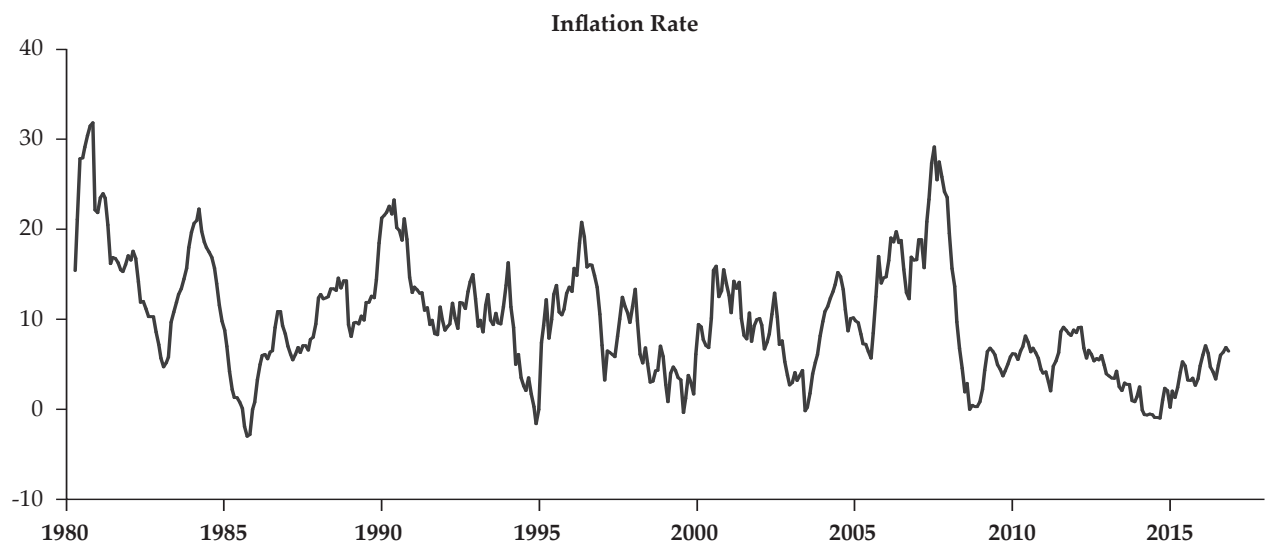


Figure 1.

Movements of the Inflation and Output Growth in Levels (Continued)

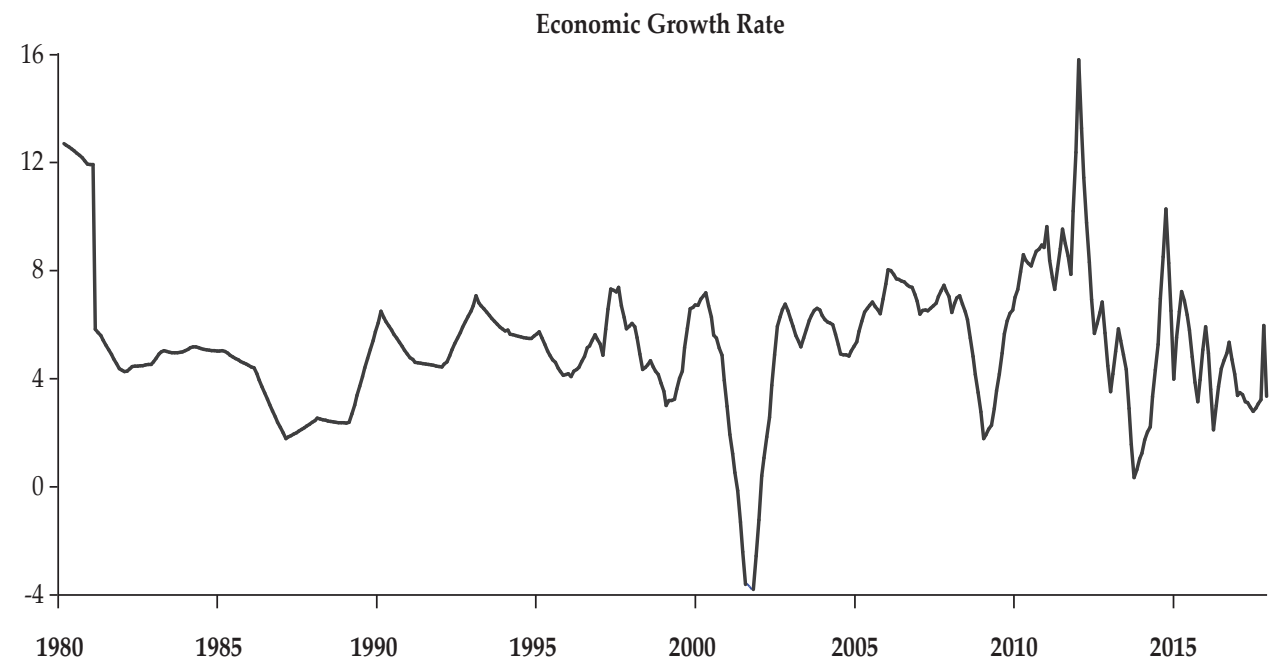

\section{B. Methodology}

B1. Estimation of Forward-looking Policy Reaction Functions

Though the literature on interest rate rules typically accounts only for inflation and the output gap, we augment the Taylor rule with both fiscal and nonfiscal variables. Several empirical studies show that the exchange rate pass-through levels are high in many emerging economies and play an important role in maintaining external competitiveness; see Mohanty and Klau (2004) and references therein. In addition, open economy policy reaction functions play a significant role in the conduct of monetary policy in both emerging and developing economies. Hence, we include the exchange rate in our policy reaction function to represent the open economy. Moreover, we consider a lagged interest rate to assume that the monetary authority in Sri Lanka tries to smooth the interest rate and changes its policy rates gradually in response to economic fluctuations (Woodford, 2002). The interest rate smoothing implies that the interest rates will be autocorrelated over time.

Since lack of fiscal discipline is incompatible with the goal of price stability, fiscal variables are considered to play an important role in the monetary policy strategy of many developing economies (Allard, Catenaro, Vidal, and Wolswijk, 2013). Sri Lanka is no exception in this regard. It is subject to fiscal constraint over periods, and we therefore include fiscal deficit in the augmented Taylor rule. This allows us to capture the role of fiscal policy in explaining the dynamic behavior of the nominal interest rate in Sri Lanka (Bodea and Higashijima, 2017).

The augmented Taylor rule to be estimated is specified as follows:

$$
\begin{aligned}
& i_{t}=(1-\rho)\left\{\bar{r}+\pi^{*}+\beta_{\pi}\left(E \pi_{t+k}-\pi^{*}\right)+\beta_{\pi}\left(E y_{t+p}-y_{t+p}^{*}\right)+\beta_{e x} \Delta e x_{t}\right. \\
& i_{t}=(1-\rho)\left\{\beta_{0}+\beta_{\pi} \pi d e v_{t}+\beta_{y} y_{g a p_{t}}+\beta_{e x} \Delta e x_{t}+\beta_{f d} f d_{t}\right\}+\rho i_{t-i}+\varepsilon_{t}
\end{aligned}
$$


where $t$ is the year index, $E$ is the expectations operator, $\pi$ dev is the inflation's deviation from the targeted level, ygap is the output gap, $\Delta e x$ is the first difference of the exchange rate, and $f d$ is the fiscal deficit. Following Equation (3), the short-term nominal interest rate responds to inflation deviations, the output gap, nominal exchange rate depreciation, and the fiscal deficit. The parameter $\rho$ measures the degree of interest rate smoothing. The coefficients $\beta_{\pi^{\prime}} \beta_{y^{\prime}} \beta_{e x}$ and $\beta_{f d}$ represent the central bank's response to changes in inflation, the output gap, nominal exchange rate depreciation, and the fiscal deficit respectively. A positive sign for the coefficient of fiscal deficit suggests that the nominal interest rate should be increased when the fiscal deficit increases. In other words, the monetary policy should be tightened when the economy experiences rapid growth of the fiscal deficit, and monetary policy easement should be pursued when the fiscal deficit growth rate decreases. The term $\varepsilon_{t}$ is an uncorrelated monetary policy shock that follows a first-order autoregressive specification and is assumed to be a white noise process.

Empirical studies find that a forward-looking policy reaction function is more realistic than a backward-looking one (Clarida et al., 1998, 2000). Hence, many central banks use the expected future inflation and output gap to determine their policy rates. Thus, we estimate the augmented policy reaction functions given in Equations (2) and (3) under forward-looking specifications. We begin with estimating the forward-looking policy reaction functions excluding the fiscal deficit. Thereafter, we will include the fiscal deficit along with other variables, such as the exchange rate, the output gap, and inflation. The forward-looking policy reaction functions are estimated for both the full-sample and subsample periods. The generalized method of moments (GMM) has become the most relevant method to estimate forward-looking rational expectations models, and the empirical literature often uses the GMM to estimate forward-looking policy reaction functions (Clarida et al., 2000). The present study also uses the GMM approach to estimate the augmented forward-looking policy reaction functions. Throughout the analysis, we assume that the CBSL follows an independent monetary policy.

\section{Analytical Framework}

Since our sample involves the period around Sri Lanka's introduction of the flexible exchange rate in January 2001 and the end of the Sri Lankan Civil War in 2009, we focus in particular on the presence of the structural break in the monetary policy in Sri Lanka. ${ }^{5}$ The start of the period in 1980 corresponds to the introduction of a monetary targeting framework in Sri Lanka. The entire sample period will be divided into three subperiods. Since the country adopted a flexible exchange rate in January 2001, we consider the first sample period to be from January 1980 to December 2000. The civil war that started in 1983 ended in May 2009; therefore, the second and third periods run from January 2001 to May 2009 and from June 2009

\footnotetext{
5 In this study, we do not undertake a formal structural break test since it is the scope of the paper; however, future studies follow Sharma et al. (2019) and Sharma (2019) can study break dates using the Narayan and Popp $(2010,2013)$ test.
} 
to December 2017, respectively. The analysis is conducted for both the full-sample and subperiods. The stationary properties of all the series considered in this study are tested using the augmented Dickey-Fuller (ADF) and Phillips-Perron tests. The unit root test will be carried out at both the levels and first differences of each series, while the Akaike information criterion with a default lag order will be used to select the order of augmentation in the ADF regression. Since the Schwarz information criterion is widely known as a parsimonious model and selects the smallest possible lag length, we use it to select the optimal lag length in this study (Babu and Rao, 2004).

\section{EMPIRICAL RESULTS AND DISCUSSION}

\section{A. Sri Lanka's Forward-looking Monetary Policy Reaction Function}

In this section, we first examine the stationary properties of the variables and then estimate the forward-looking Taylor curve with and without the fiscal deficit for the period from 1980 to 2017. The results of unit root tests are presented in Table 1. The results confirm that four variables are nonstationary, since the null hypothesis of the ADF and Phillips-Perron tests cannot be rejected at the $5 \%$ level of significance. However, the remaining variables are found to be integrated with order one.

\section{Table 1.}

\section{Unit Root Tests}

This table reports results from unit root tests. Panel A has ADF test results while Panel B contains PP test results. Both tests are conducted on the levels and first difference of the variables and for a model that includes (i) intercept only and (ii) intercept and trend. The list of variables appears in column 1 . Finally, $\left.{ }^{*}{ }^{* *}\right)^{* * *}$ indicate statistical significance at the $1 \%(5 \%) 10 \%$ levels.

\begin{tabular}{|c|c|c|c|c|c|c|c|c|c|}
\hline \multirow[b]{3}{*}{ Variable } & \multicolumn{4}{|c|}{ Panel A: ADF Test } & \multicolumn{4}{|c|}{ Panel B: PP Test } & \multirow[b]{3}{*}{$\begin{array}{c}\text { Order of } \\
\text { Integration }\end{array}$} \\
\hline & \multicolumn{2}{|c|}{ Levels } & \multicolumn{2}{|c|}{ First Differences } & \multicolumn{2}{|c|}{ Levels } & \multicolumn{2}{|c|}{ First Differences } & \\
\hline & Intercept & $\begin{array}{c}\text { Trend } \\
\text { and } \\
\text { Intercept }\end{array}$ & Intercept & $\begin{array}{c}\text { Trend } \\
\text { and } \\
\text { Intercept }\end{array}$ & Intercept & $\begin{array}{c}\text { Trend } \\
\text { and } \\
\text { Intercept }\end{array}$ & Intercept & $\begin{array}{c}\text { Trend } \\
\text { and } \\
\text { Intercept }\end{array}$ & \\
\hline CPI & 4.9022 & -0.6368 & $-11.0026^{*}$ & $-16.8477^{*}$ & 4.2141 & -0.6790 & $-17.5240^{*}$ & $-17.6984^{*}$ & $\mathrm{I}(1)$ \\
\hline RGDP & $-4.6868^{*}$ & $-4.7417^{*}$ & $-9.8796^{*}$ & $-9.8748^{*}$ & $-4.3089^{*}$ & $-4.3365^{*}$ & $-13.9667^{*}$ & $-13.9462^{*}$ & $\mathrm{I}(0)$ \\
\hline TBILL & $-2.9338^{* *}$ & $-3.7319^{* * *}$ & $-13.6918^{*}$ & $-13.6981^{*}$ & $-3.0159^{* * *}$ & $-3.7901^{*}$ & $-23.2074^{*}$ & $-23.2056^{*}$ & $\mathrm{I}(0)$ \\
\hline EXR & 0.6854 & -2.7292 & $-8.9320^{*}$ & -9.0061 & 1.0176 & -2.2981 & $-14.8817^{*}$ & $-14.9416^{*}$ & $\mathrm{I}(1)$ \\
\hline$F B$ & $-2.7957^{* * * *}$ & $-3.4580^{* * *}$ & $-7.3576^{*}$ & $-7.3784^{*}$ & $-3.6453^{*}$ & $-4.0928^{*}$ & $-17.2131^{*}$ & $-17.2032^{*}$ & $\mathrm{I}(0)$ \\
\hline
\end{tabular}

As shown in Figure 1, neither inflation nor economic growth exhibits any trend over the periods. The Sri Lankan economy registered an inflation rate greater than $30 \%$ during the early 1980s. However, this figure declined till 1985, but thereafter escalated until the early part of the 1990s. This trend shows that Sri Lanka 
experienced very high levels of inflation during the 1980s and 1990s, suggesting that inflation variability must have had a much lower weight in the policymaker's loss function. However, after late 2009, the inflation rate was at single-digit levels. Meanwhile, during the study period, the economy witnessed an average growth rate of $5 \%$. Especially high levels of economic growth can be observed following the end of the civil war, in 2009. However, the fluctuations in the inflation rate are greater than those of the economic growth rate.

During the sample period, the variability of inflation decreases while the variability of output increases, implying an unambiguous improvement in macroeconomic performance. This result further indicates that the central bank predominantly considered implicit inflation targeting more important. The graph in Figure 1 also highlights that low inflation variability was attained at the expense of increased output variability.

Figure 2.

Movements of the Variability of Inflation and Output Growth

This figure plots two series-the difference of the inflation rate and the difference of the economic growth rate. The time-series data are from 1980 to 2017.
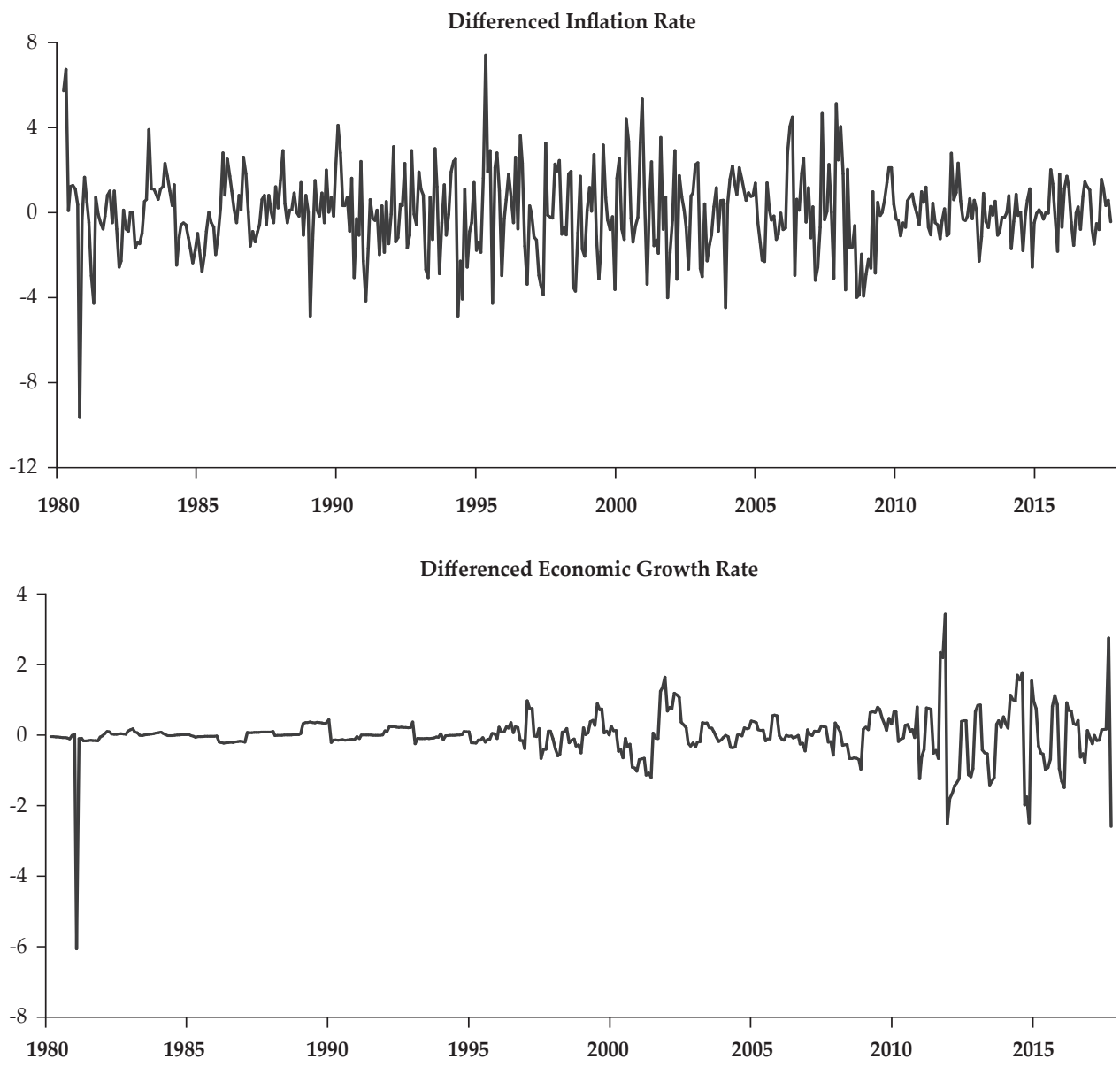
According to Figure 2, the volatility of inflation is much higher compared to that of output growth. Although a high level of inflation volatility is observed prior to 2010, volatility diminishes afterward. This finding implies that the Sri Lankan economy experienced a transition from relatively higher volatile inflation regimes at the beginning of the study period to more stable regimes thereafter. The reduced volatilities in inflation could be largely supported by the low level of external and domestic supply shocks, a more stable economic structure, and the implementation of better monetary policy (Jegajeewan, 2016). The volatility of output growth was almost stable until the end of 1995; however, it increased gradually after 1996. Notably, much greater volatility is observed after 2010.

After examining the properties of the variables, we estimate the forwardlooking open economy policy reaction functions for Sri Lanka. We consider the three-month Treasury bill rate as the monetary policy instrument. Further, we assume that the central bank responds to changes in inflation, the output gap, and the exchange rate while focusing on smoothness in the interest rate. Since the conduct of monetary policy changes over the periods, the behavior of the central bank also changes. Therefore, to account for structural breaks, we estimate the policy reaction function for each subsample period separately. The results are presented in Table 2 . They show that the $p$-values for the estimated $J$-statistic ${ }^{6}$ are significantly above $5 \%$. This finding suggests that the null hypothesis of the model being correctly specified cannot be rejected, even at the $10 \%$ level of significance. The results show that the estimated policy reaction functions had adequate restrictions and that all the models are correctly specified. This further confirms that the estimated functions satisfy all the moment restrictions.

Table 2.

\section{Forward-Looking Policy Reaction Functions}

This table reports results from the forward-looking policy reaction functions. Column 2 notes results for the fullsample period (1980-2017) while the rest of the three columns have results for each of the three regimes, namely the period 1980-2000 (regime 1), 2001-2009 (regime 2), and 2009-2017 (regime 3). Finally, ${ }^{*}{ }^{* *}$ ) ${ }^{* * *}$ indicate statistical significance at the $1 \%$ (5\%) $10 \%$ levels.

\begin{tabular}{lcccc}
\hline Variable & $\begin{array}{c}\text { Period } \\
\text { 1980-2017 } \\
\text { (Full Sample) }\end{array}$ & $\begin{array}{c}\text { Regime 1 } \\
\mathbf{( 1 9 8 0 - 2 0 0 0 )}\end{array}$ & $\begin{array}{c}\text { Regime 2 } \\
(\mathbf{2 0 0 1 - 2 0 0 9 )}\end{array}$ & $\begin{array}{c}\text { Regime 3 } \\
(\mathbf{2 0 0 9 - 2 0 1 7 )}\end{array}$ \\
\hline$\beta_{0}$ & 5.4865 & 10.5218 & -10.5812 & -3.9490 \\
$\beta_{\pi}$ & $(1.6815)$ & $(2.0454)$ & $(2.4398)$ & $(16.8019)$ \\
$\beta_{y}$ & $0.6074^{* * *}$ & 0.1939 & $1.9139^{* * *}$ & $1.8604^{* * *}$ \\
$\beta_{e x}$ & $(0.1514)$ & $(0.1766)$ & $(0.2040)$ & $(0.2228)$ \\
& $1.1839^{* * *}$ & 0.7598 & $1.2236^{* * *}$ & $1.4850^{* *}$ \\
$\rho$ & $(0.3127)$ & $(0.5591)$ & $(0.5132)$ & $(1.7780)$ \\
& $0.0675^{* * *}$ & $0.3595^{* * *}$ & $0.2281^{* * *}$ & $0.0794^{* * *}$ \\
& $(0.0096)$ & $(0.1136)$ & $(0.0139)$ & $(0.0173)$ \\
& $0.9652^{* * *}$ & $0.9167^{* * *}$ & $0.9748^{* * *}$ & $0.9897^{* * *}$ \\
& $(0.0064)$ & $(0.0288)$ & $(0.0024)$ & $(0.0154)$ \\
\hline
\end{tabular}

\footnotetext{
6 The J-statistic is used to test for overidentifying restrictions in the models estimated using the GMM approach.
} 
Table 2.

Forward-Looking Policy Reaction Functions (Continued)

\begin{tabular}{lcccc}
\hline Variable & $\begin{array}{c}\text { Period } \\
\text { 1980-2017 } \\
\text { (Full Sample) }\end{array}$ & $\begin{array}{c}\text { Regime 1 } \\
\mathbf{( 1 9 8 0 - 2 0 0 0 )}\end{array}$ & $\begin{array}{c}\text { Regime 2 } \\
\mathbf{( 2 0 0 1 - 2 0 0 9 )}\end{array}$ & $\begin{array}{c}\text { Regime 3 } \\
\mathbf{( 2 0 0 9 - 2 0 1 7 )}\end{array}$ \\
\hline No. of. Obs. & 432 & 228 & 76 & 79 \\
Adj. R-squared & 0.9291 & 0.7878 & 0.9692 & 0.9276 \\
S.E. of Regression & 0.9450 & 0.9451 & 0.6556 & 0.4124 \\
Durbin-Watson Stat. & 2.0339 & 2.1304 & 2.1038 & 1.9821 \\
J-Statistic & 17.2703 & 9.3424 & 14.5156 & 10.3648 \\
Prob. (J-Statistic) & $(0.4362)$ & $(0.3266)$ & $(0.1272)$ & $(0.8876)$ \\
Instrument Rank & 22 & 22 & 22 & 22 \\
\hline
\end{tabular}

This study finds that the coefficients of the estimated policy reaction functions change with different magnitudes. The estimates of $\beta_{\pi}$ have the expected sign and are significant in all periods, except from 1980 to 2000. However, the results show that the coefficients differ considerably across policy regimes. During the period from 1980 to 2000, the estimated coefficient is nonsignificant and less than one (0.1939), indicating that the first Taylor principle does not hold in this period. This finding further confirms that the monetary policy was passive during this period. Violation of the Taylor principle could be an important factor that partly contributes to the high levels of inflation that Sri Lanka experienced from 1980 to 2000. However, the estimated coefficients have a significant positive sign in the remainder of the policy reaction functions. The coefficients are significantly above one for the periods from 2001 to 2009 (1.9139) and from 2009 to 2017 (1.8604), which indicates that the CBSL satisfied the first Taylor principle. Thus, an increase in expected future inflation increases the probability of the policy rate being raised during these periods. These estimations are consistent with recent results in the literature. For example, Ehelepola (2015) estimates an inflation coefficient of 1.18 and shows that the CBSL responded to inflation more aggressively compared to the past.

The estimated coefficients of $\beta_{y^{\prime}}$ which measures the reactions of the interest rate to the output gap, had, as expected, a significant and positive impact on the policy rates in all the estimated reaction functions, except for the first regime. This result implies that the second Taylor principle fails to hold only during the period from 1980 to 2000. Although the estimated policy reaction function for the full sample shows that the CBSL paid greater attention to stabilization of the output, compared to inflation, the reaction functions estimated for the different policy regimes show that the policymakers reacted aggressively to stabilize both output and inflation. This is particularly notable during the second and third regimes. The results further show that the size of the inflation coefficient increases over time, compared to the output gap, reflecting the CBSL's greater focus on price stability. These results are consistent with those of Perera and Jayawickrama (2013) for Sri Lanka. 
Although, the exchange rate is not a standard variable in policy reaction functions, we find that the estimated coefficients for $\beta_{e x}$ are positive and significant in all four reaction functions. This result indicates that the CBSL reacted to nominal exchange rate depreciation by tightening monetary policy. The magnitude of the coefficient is found to be large during the period from 1980 to 2000, compared to other periods. If the Sri Lankan rupee depreciates against the US dollar, one would expect the central bank to increase its policy rates to offset the depreciation of the domestic currency. These results are consistent with previous research by Ehelepola (2015), who shows that the magnitude of the exchange rate coefficient is positive and significant but very low for Sri Lanka. However, these results contradict some of the previous literature. For example, Patra and Kapoor (2012) find that the exchange rate is nonsignificant in their policy reaction functions they estimate for India, and they therefore conclude that policy rates were not used to target a level or band of the exchange rate. Similarly, McCauley (2006) finds that the central bank did not react to changes in the exchange rate and that the authorities used other instruments to minimize the adverse impacts of the depreciation of domestic currency. The empirical literature also argues that the strength of policy reaction functions in response to exchange rate depreciation depends on whether the central bank can use other instruments besides interest rates (Mohanty and Klau, 2004).

The results further disclose that the estimated smoothing coefficients $(\rho)$ are positive and significantly higher in all the reaction functions. These results confirm significant interest rate inertia, despite changes in the conduct of monetary policy across different policy regimes. Our results further confirm the conventional wisdom that the central bank seeks smoothness by adjusting the interest rate. This suggests that the CBSL changes its policy rates gradually in response to macroeconomic developments.

\section{B. Response to Fiscal Deficit by the CBSL}

Since both the theoretical literature and empirical literature show a clear long-run relation between the fiscal deficit and inflation, independent central banks pay greater attention to fiscal discipline and pursue their fiscal policy preferences by adjusting their policy rates (Sidaui, 2003; Piergallini, 2006; De Haan and Eijffinger, 2016). In the case of Sri Lanka, since the prices of several items, including energy and transport services, are administered by the government, supply shocks emerging from fiscal policy are particularly important in maintaining price stability. This setting forces the monetary authority to pay great attention to the developments on the fiscal front. In this section, we therefore estimate forwardlooking policy reaction functions incorporating the fiscal deficit to account for the role of fiscal variables in determining interest rates. The estimated results are presented in Table 3 and show that the $p$-values for the estimated J-statistics are significantly above $5 \%$. This finding suggests that the null hypothesis of the model being correctly specified cannot be rejected, and we can therefore conclude that all the policy reaction functions are correctly specified. 
Table 3.

\section{Forward-Looking Policy Reaction Functions with Fiscal Deficit}

This table reports results from the forward-looking policy reaction functions with fiscal deficit. Column 2 notes results for the full-sample period (1980-2017) while the rest of the three columns have results for each of the three regimes, namely for the period 1980-2000 (regime 1), 2001-2009 (regime 2), and 2009-2017 (regime 3). Finally, $\left.{ }^{*}{ }^{* *}\right)^{* * *}$ indicate statistical significance at the $1 \%(5 \%) 10 \%$ levels.

\begin{tabular}{lcccc}
\hline Variable & $\begin{array}{c}\text { Period } \\
\text { 1980-2017 } \\
\text { (Full Sample) }\end{array}$ & $\begin{array}{c}\text { Regime 1 } \\
\mathbf{( 1 9 8 0 - 2 0 0 0 )}\end{array}$ & $\begin{array}{c}\text { Regime 2 } \\
(\mathbf{2 0 0 1 - 2 0 0 9 )}\end{array}$ & $\begin{array}{c}\text { Regime 3 } \\
(\mathbf{2 0 0 9 - 2 0 1 7 )}\end{array}$ \\
\hline $\boldsymbol{\beta}_{0}$ & 3.4758 & 13.2376 & -14.8080 & 8.2722 \\
$\boldsymbol{\beta}_{\pi}$ & $(1.8686)$ & $(2.5445)$ & $(2.6079)$ & $(2.1849)$ \\
$\boldsymbol{\beta}_{y}$ & $0.7347^{* * *}$ & $3.11634^{* *}$ & $1.8905^{* * *}$ & $0.3721^{* * *}$ \\
& $(0.1707)$ & $(1.4864)$ & $(0.1908)$ & $(0.1055)$ \\
$\boldsymbol{\beta}_{e x}$ & $1.4067^{* * *}$ & -0.9509 & -0.3466 & -0.1119 \\
& $(0.3883)$ & $(0.6439)$ & $(0.2324)$ & $(0.1344)$ \\
$\rho$ & $0.0705^{* * *}$ & $0.3798^{* * *}$ & $0.1529^{* * *}$ & $0.0415^{* *}$ \\
& $(0.0084)$ & $(0.0991)$ & $(0.0054)$ & $(0.0206)$ \\
$\boldsymbol{\beta}_{f d}$ & $0.9660^{* * *}$ & $0.8976^{* * *}$ & $0.9703^{* * *}$ & $0.9207^{* * *}$ \\
No. of. Obs. & $(0.0056)$ & $(0.0298)$ & $(0.0030)$ & $(0.0197)$ \\
Adj. R-squared & 0.0026 & 0.0032 & 0.0963 & 0.0404 \\
S.E. of Regression & $(0.0103)$ & $(0.0271)$ & $(0.0758)$ & $(0.0360)$ \\
Durbin-Watson Stat. & 432 & 228 & 76 & 79 \\
$J$ J-Statistic & 0.9324 & 0.7827 & 0.9677 & 0.9287 \\
Prob. (J-Statistic) & 0.9229 & 0.5068 & 0.6709 & 0.4252 \\
Instrument Rank & 2.1341 & 2.0782 & 2.1047 & 1.9847 \\
\hline
\end{tabular}

The estimated parameters of the output gap, inflation, the fiscal deficit, and the exchange rate are also found to vary across different monetary policy regimes. The results show that the CBSL responds significantly to inflation in both the fullsample and subsample analysis. According to the reaction functions, monetary policy in Sri Lanka was active during the periods from 1980 to 2000 and from 2001 to 2009 , but passive from 2009 to $2017 .{ }^{7}$ Moreover, the coefficients of the fiscal deficit are positive but nonsignificant. Hence, there is substantial evidence to show that the CBSL did not react to the movements of fiscal deficit during the period under investigation. Since there is no literature on the role of the fiscal deficit in the policy reaction function for the case of Sri Lanka, this study provides fresh empirical evidence on the reaction of the interest rate to the fiscal deficit.

Although this study shows that the output gap coefficient for the fullsample analysis is significant, interestingly, the coefficient becomes negative and statistically nonsignificant in the subsample analysis. This finding implies that the CBSL does not satisfy the second Taylor principle, even though the coefficient of

\footnotetext{
7 The estimates of the inflation parameter that satisfy the Taylor principle are regarded as indicating active monetary policy regimes, whereas the coefficients for inflation that are less than one are classified as indicating passive monetary policy regimes.
} 
inflation is statistically significant and satisfies the benchmark value suggested by Taylor (1993). This challenges results obtained while excluding fiscal deficit. The negative and nonsignificant coefficients for the output gap could be due to the inclusion of the fiscal deficit in the policy reaction functions (Sidaui, 2003). Another reason could be measurement error in estimating the output gap.

Additionally, the results show that the reaction of the interest rate to the exchange rate is positive and statistically significant. This finding is consistent with our previous results and robust to different modifications of the Taylor rule. The CBSL therefore reacted to nominal exchange rate depreciation by tightening monetary policy. Moreover, the coefficients for the lagged interest rate appeared positive and significant in all the estimated policy reaction functions, showing a high degree of interest rate smoothing by the CBSL. This finding further indicates that the CBSL changes its policy rates in small steps in response to macroeconomic developments. However, the degree of smoothness decreases gradually over the periods. Notably, the coefficient that increases from 0.89 in the period 1980-2000 to 0.97 in the period 2001-2009 gradually drops to 0.92 during the period 2009-2017. These results allow us to conclude that interest rate smoothing, exchange rate stability, and price stability play a greater role in determining the interest rate than the output gap does. Additionally, after we incorporate the fiscal deficit, we find the first Taylor principle to be satisfied in all the policy reaction functions, except for the period from 2009 to 2017 . However, since the coefficients of the fiscal deficit are nonsignificant for all the policy reaction functions, one can conclude that the policy reaction functions estimated excluding the fiscal deficit are more accurate for Sri Lanka.

\section{CONCLUSION}

This study estimates the forward-looking monetary policy reaction function for Sri Lanka using monthly data from 1980 to 2017. The estimated forward-looking policy reaction functions for the full sample and subsamples provide mixed results. The study finds that the coefficients of the estimated forward-looking policy reaction functions differ across the periods in terms of sign, size, and statistical significance. Based on a forward-looking open economy monetary reaction function for the full sample, we find that the reaction of policymakers to fluctuations in the output gap has been greater than their response to inflation. More specifically, the first Taylor principle does not hold for the full-sample period. Meanwhile, the coefficient on the output gap is above unity, confirming that policymakers paid more attention to stabilization of the output. However, the subsample analysis shows contradicting results.

The analysis confirms the satisfaction of the Taylor principle in all periods, except from 1980 to 2000 . The study further reveals that policymakers reacted to nominal exchange rate depreciation by tightening monetary policy in both the full-sample and the subsample analysis. Moreover, the study finds that the CBSL changed its policy rates gradually in response to macroeconomic developments, though the degree of smoothness was gradually reduced over time. The subsample analysis further shows that the size of the coefficient on inflation increases over time, reflecting greater focus on price stability. Meanwhile, the estimated forward- 
looking reaction function that considers the fiscal deficit provides substantial evidence to confirm that the monetary authority in Sri Lanka did not react to movements in the fiscal deficit during the period under investigation. Although the study finds that the output gap for the full sample is significant, it is interesting to note that the coefficient of the output gap becomes negative and statistically nonsignificant in all the subsample analyses after the fiscal deficit is added in the policy reaction functions. It is also worth mentioning that neither the Taylor rule nor the Taylor principle is satisfied in the reaction function specifications after the incorporation of fiscal deficit.

Thus, it can be concluded that augmented policy reaction functions that ignore the fiscal deficit appear to capture the behavior of the monetary authority in Sri Lanka more accurately. Since there is less evidence available in the empirical literature on the Taylor rule for developing countries, the findings of this study provide incentives to propose a rule-based monetary policy for developing economies.

Acknowledgement: The author is grateful to the participants at the Bulletin of Monetary Economics and Banking Conference 2019 for their valuable comments and suggestions. The author is also thankful for the comments and suggestions of the anonymous reviewers. The views expressed in this paper are the author's own and do not reflect the views of the Central Bank of Sri Lanka.

\section{REFERENCES}

Allard, J., Catenaro, M., Vidal, J., \& Wolswijk, G. (2013). Central Bank Communication on Fiscal Policy, 1477. European Journal of Political Economy, 30, 1-13.

Babu, G. J., \& Rao, C. R. (2004). Goodness-of-fit Tests when Parameters are Estimated. Sankhya, 66, 63-74.

Bernanke, B.S. (2010). Central Bank Independence, Transparency, and Accountability. Speech of Chairman Ben S. Bernanke at the Institute for Monetary and Economic Studies International Conference, Bank of Japan, Tokyo, Japan May 25, 2010.

Bodea, C., \& Higashijima, M. (2017). Central Bank Independence and Fiscal Policy: Can the Central Bank Restrain Deficit Spending? British Journal of Political Science, 47, 47-70.

Chuku, C., \& Middleditch, P. (2016). Characterizing Monetary and Fiscal Policy Rules and Interactions when Commodity Prices Matter. Centre for Growth and Business Cycle Research (CGBCR) Discussion Paper Series, Economic Studies, University of Manchester, Manchester, 222.

Clarida, R., Gali, J., \& Gertler, M. (1998). Monetary Policy Rules and Macroeconomic Stability: Evidence and Some Theory. National Bureau of Economic Research, Inc.

Clarida, R., Gali, J., \& Gertler, M. (2000). Monetary Policy Rules and Macroeconomic Stability: Evidence and Some Theory. The Quarterly Journal of Economics, 115, 147-180. 
De Haan, J., \& Eijffinger, S. C. W. (2016). The Politics of Central Bank Independence. De Nederlandsche Bank Working Paper No. 539.

Ehelepola, K. (2015). An Estimated Open Economy New Keynesian DSGE Model for Sri Lanka with Monetary and Fiscal rules. Conference Proceedings, Eighth International Conference, Central Bank of Sri Lanka.

Fackler, J. S., \& McMillin, W. D. (2011). Inflation Forecast Targeting: An Alternative Approach to Estimating the Inflation-Output Variability Tradeoff. Southern Economic Journal, 78, 424-451.

Fox, J. (2000). Nonparametric Simple Regression: Smoothing Scatterplots (No. 130) Sage. Ghosh, A.R., Ostry, J.D., \& Chamon, M., (2016). Two targets, Two Instruments: Monetary and Exchange rate Policies in Emerging Market Economies. Journal of International Money and Finance, 60, 172-196.

Gray, C. (2012), Responding to a Monetary Superpower: Investigating the Behavioral Spillovers of U.S. Monetary Policy, Department of Economics, Stanford University.

Jawadi, F., Mallick, S.K., \& Sousa, R.M., (2014). Nonlinear Monetary Policy Reaction Functions in Large Emerging Economies: The Case of Brazil and China. Applied Economics, 46, 973-984.

Jegajeewan, S. (2016). Understanding Sri Lankan Business Cycles through an Estimated DSGE Model. Conference Proceedings, Ninth International Conference, Central Bank of Sri Lanka.

Jung, A. (2018). Does Mccallum's Rule Outperform Taylor's Rule During the Financial Crisis? Quarterly Review of Economics and Finance. 69. 9-21.

Konuki, T. (2010). Estimating Potential Output and the Output Gap in Slovakia. Eastern European Economics., 48, 39-55

Kumhof, M., Nunes, R., \& Yakadina, I. (2010). Simple Monetary Rules Under Fiscal Dominance. Journal of Money, Credit and Banking, 42, 63-92.

Martin, C., \& Milas, C., 2013. Financial Crises and Monetary Policy: Evidence from the UK. Journal of Financial Stability. 9, 654-661.

McCallum, B.T., \& Nelson, E., (1999). Nominal Income Targeting in An OpenEconomy Optimizing Model. Journal of Monetary Economics, 43, 553-578.

McCauley, R, N. (2006). Understanding Monetary Policy in Malaysia and Thailand: Objectives, Instruments and Independence. Social Development, 199-203.

Miles, W., \& Schreyer, S., (2012). Is Monetary Policy Non-Linear in Indonesia, Korea, Malaysia, And Thailand? A quantile regression analysis. Asian Pacific Economic Literature, 26, 155-166.

Mohanty, M., \& Klau, M. (2004). Monetary Policy Rules in Emerging Market Economies: Issues and Evidence. BIS Working Paper No. 149, Monetary and Economic Department, Bank of International Settlements.

Narayan, P. K., \& Popp, S. (2010). A New Unit Root Test with Two Structural Breaks in Level and Slope at Unknown Time. Journal of Applied Statistics, 37, 1425-1438.

Narayan, P. K., \& Popp, S. (2013). Size and Power Properties of Structural Break Unit Root Tests. Applied Economics, 45, 721-728.

Olson, E., \& Enders, W., (2012). A Historical Analysis of The Taylor Curve. Journal of Money, Credit and Banking, 44, 1285-1299. 
Orphanides, A. (2001). Monetary Policy Rules Based on Real-Time Data. American Economic Review, 91, 964-985.

Patra, M.D., \& Kapur, M. (2012), A Monetary Policy Model for India, Macroeconomics and Finance in Emerging Market Economies, 5, 16-39.

Perera, A., \& Wickramanayake, J. (2013). Monetary Transmission in the Emerging Country Context: The Case of Sri Lanka. Conference Proceedings, Sixth International Research Conference, Central Bank of Sri Lanka.

Piergallini, A. (2006). Fiscal Deficits, Taylor Rules, And Price Dynamics. Atlantic Economic Journal, 34, 395-403.

Sargent, T. J. (2014). The Evolution of Monetary Policy Rules. Journal of Economic Dynamics and Control, 49, 147 - 150.

Sharma, S.S., Tobing, L., and Azwar, P., (2018) Understanding Indonesia's macroeconomic data: What do we know and what are the implications, Bulletin of Monetary Economics and Banking, 21, 217-250.

Sharma, S. S. (2019). Which variables predict Indonesia's inflation?. Bulletin of Monetary Economics and Banking, 22, 87-102.

Shrestha, P.K., \& Semmler, W., (2015). Monetary Policy and International Reserves in Emerging Economies: Theory and Empirics. In: Finch, N. (eds), Emerging Markets and Sovereign Risk. Palgrave Macmillan, London. 213-230.

Stephanos P. \& Vangelis A (2015). The Effect of the Market-Based Monetary Policy Transparency Index on Inflation and Output Variability, International Review of Applied Economics, 29, 105-124.

Svensson, L.E. (2003). What is Wrong with Taylor Rules? Using Judgment in Monetary Policy through Targeting Rules. Journal of Economic Literature, 41, 426-477.

Taylor, J. B. (1993). Discretion Versus Policy Rules in Practice, Carnegie-Rochester Conference Series on Public Policy, 39, 195-214.

Taylor, J. B. (2013). The Effectiveness of Central Bank Independence Versus Policy Rules. Stanford University, Business Economics, 48, 1-22.

Taylor, J. B., \& Williams, J. C. (2010). Simple and Robust Rules for Monetary Policy. In Handbook of monetary economics, 3, 829-859.

Taylor, J.B. (2000). Using Monetary Policy Rules in Emerging Market Economies. In: The 75th Anniversary Conference, "Stabilization and Monetary Policy: The International Experience". Bank of Mexico.

Taylor, J.B. (2013). International Monetary Coordination and The Great Deviation. Journal of Policy Modeling, 35, 463-472.

Woodford, M. (2001). The Taylor Rule and Optimal Monetary Policy. American Economic Review, 91, 232-237.

Woodford, M. (2002). Inflation Stabilization and Welfare. NBER Contributions in Macroeconomics, 2, 1534-6005. 


\section{Appendix}

\section{Figure A1.}

\section{Behaviour of the Variables}

The detailed descriptions of the variables are given in Table A1.

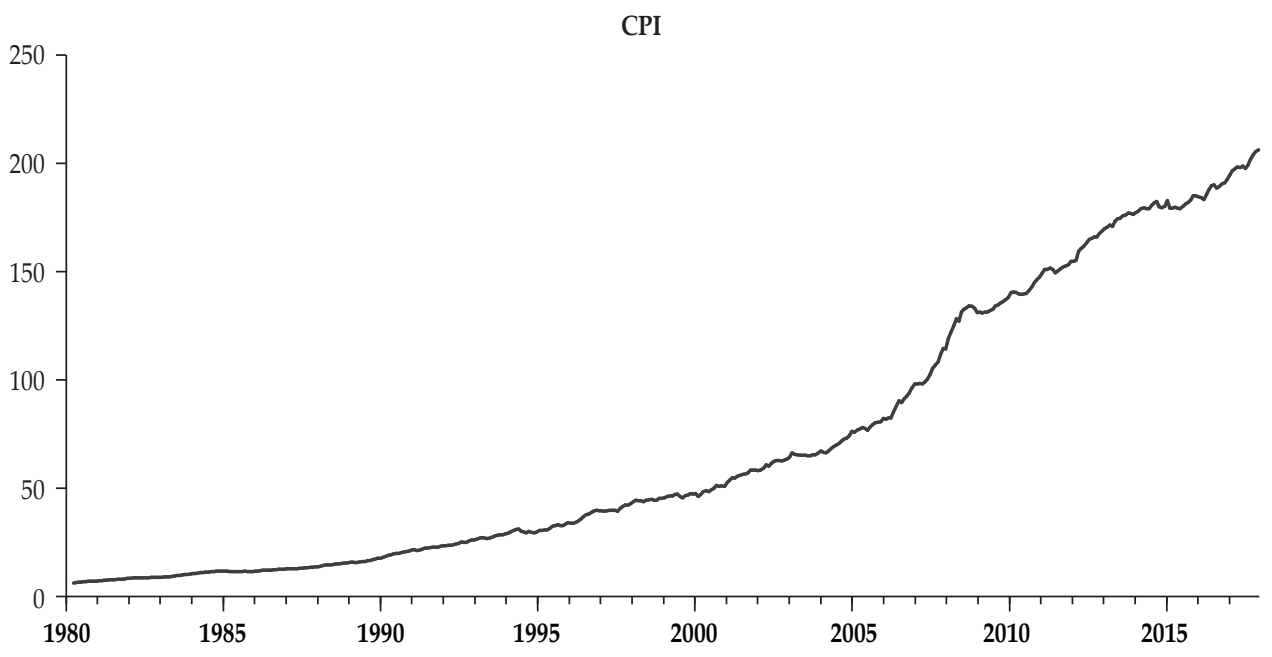

FB

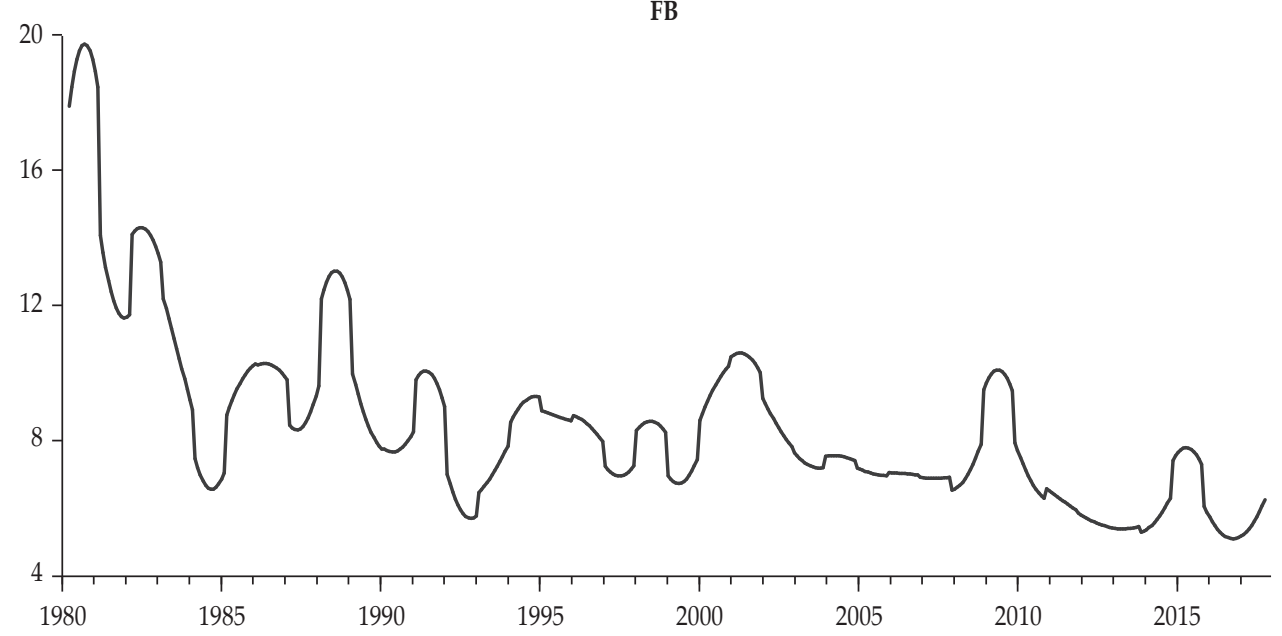


Figure A1.

Behaviour of the Variables (Continued)

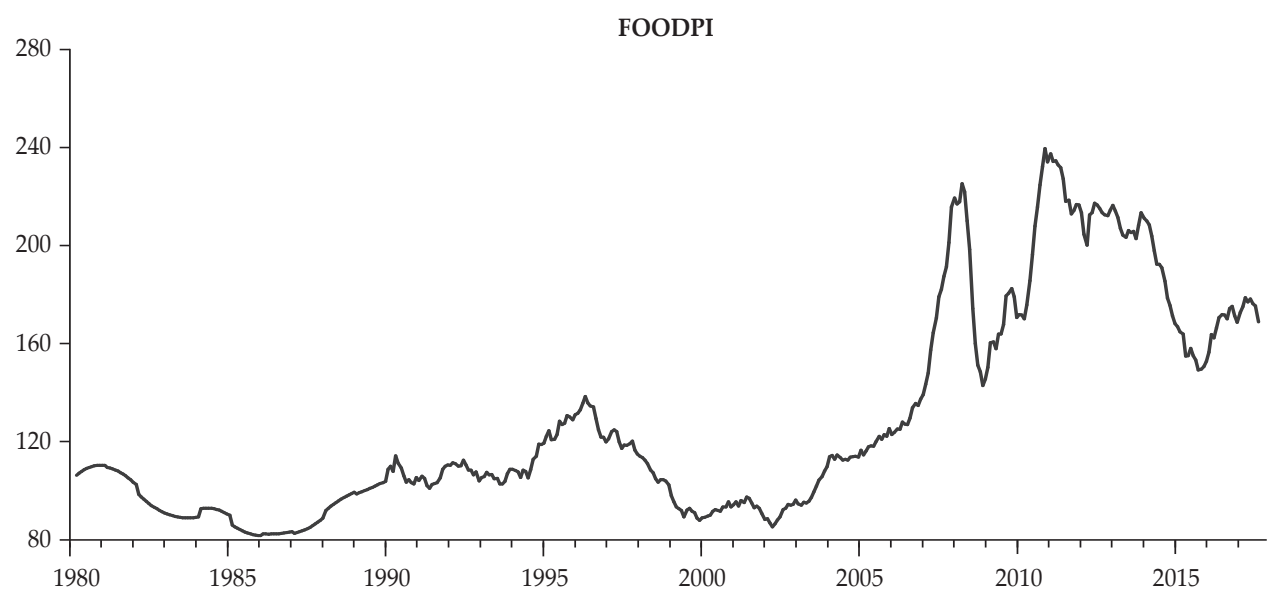

FED
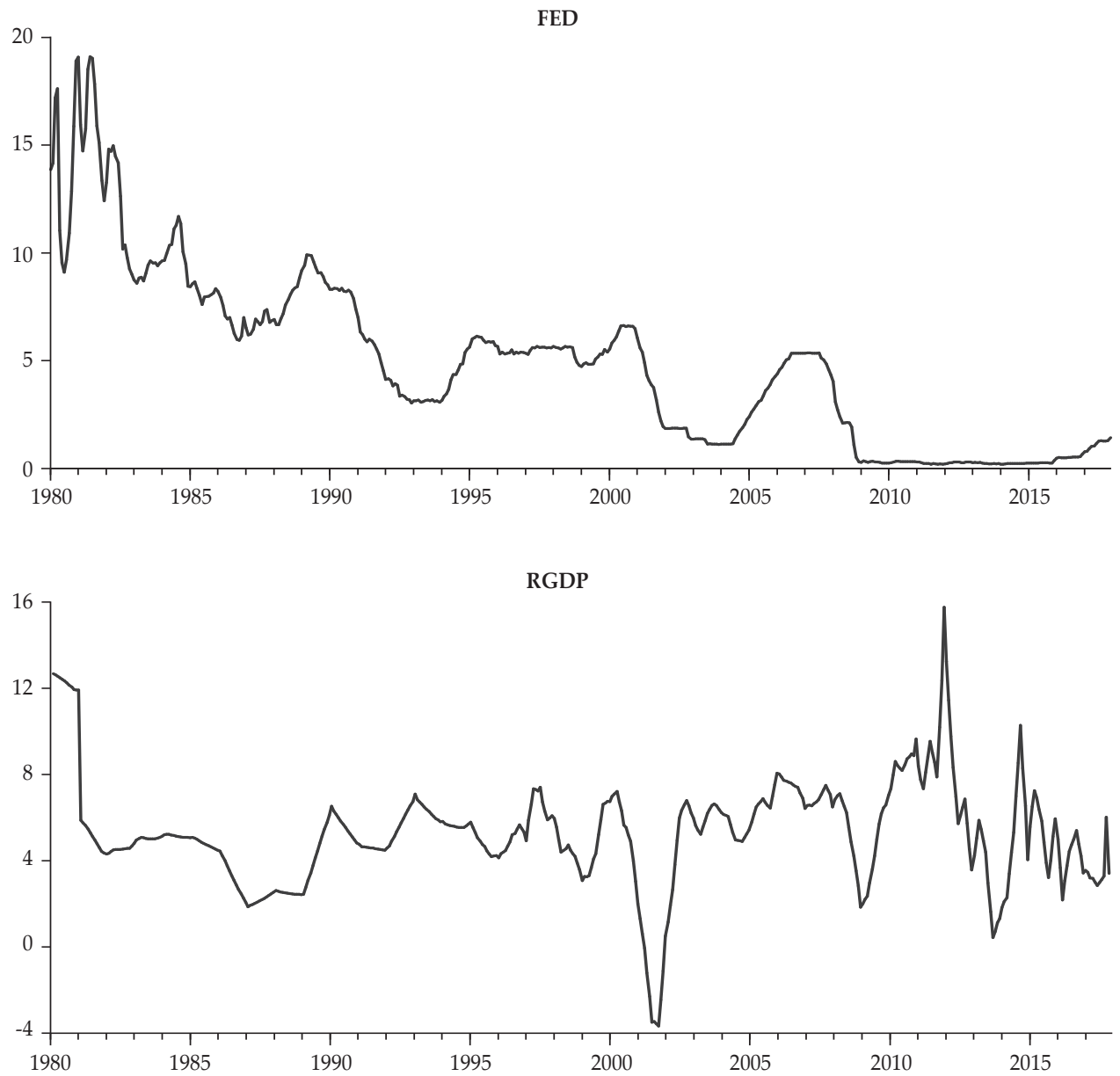
Figure A1.

Behaviour of the Variables (Continued)

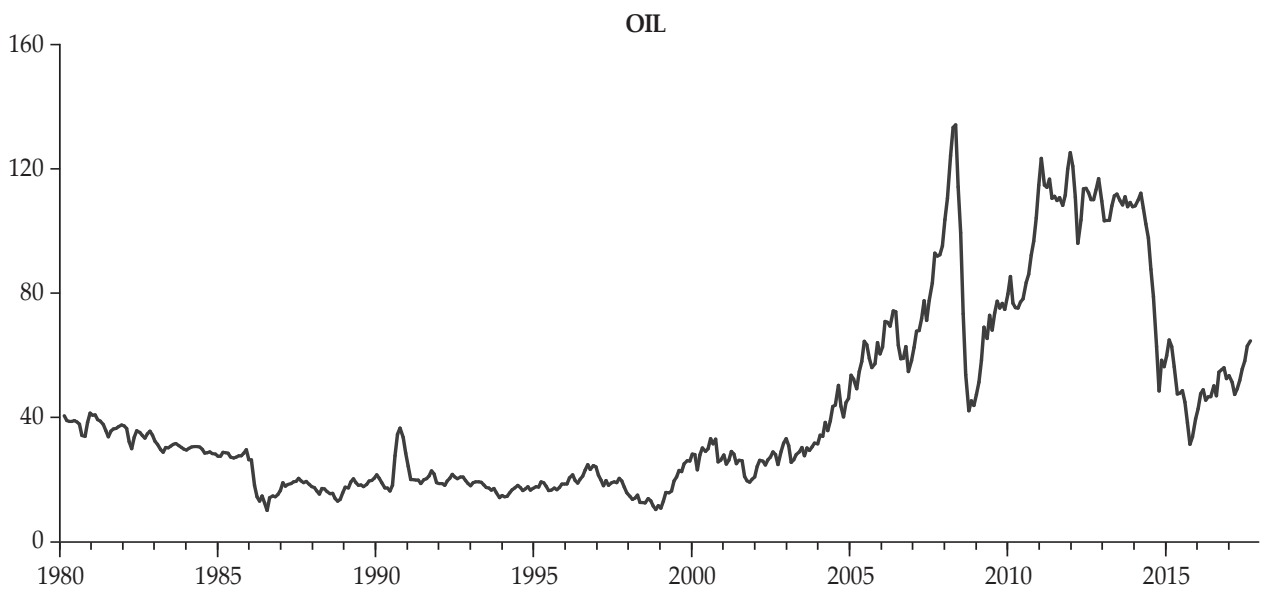

TBILL
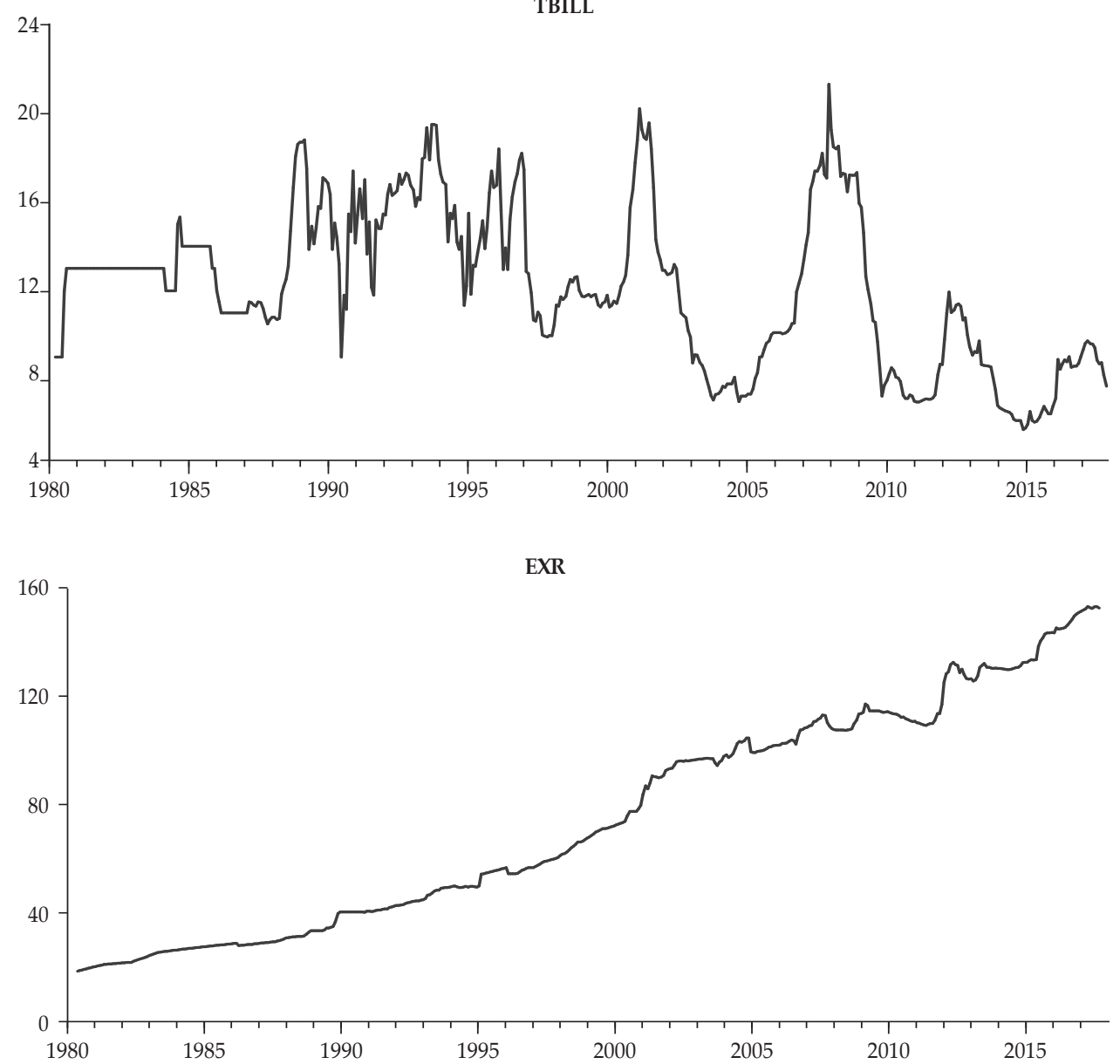
Table A1.

Definition of the Variables and Data Sources

This table presents a definition of the variables and notes their source. CBSL-Central Bank of Sri Lanka, DCSDepartment of Census and Statistics of Sri Lanka, FAO-Food and Agricultural Organization.

\begin{tabular}{lcc}
\hline Variable & Definition of Variables & Data Source \\
\hline CPI & Consumer Price Index & DCS \\
RGDP & Real GDP & DCS \\
TBILL & Shor-term Interest Rate (Tbill-3 months) & CBSL \\
EXR & Exchange Rate (USA/LKR) & CBSL \\
OIL & Brent Oil Price & Bloomberg \\
GDPGAP & Output Gap & Estimated \\
INFGAP & Inflation Gap & Estimated \\
FB & Fiscal Balance (surplus/deficit) $(\%$ of GDP) & CBSL \\
CPIRATE & Inflation Rate & DCS \\
\hline
\end{tabular}

Table A2.

Descriptive Statistics of the Variables (Full Sample)

The detailed description of the variables is given in Table A1.

\begin{tabular}{lcccccc}
\hline Description & CPI & CPIRATE & RGDP & TBILL & EXR & FB \\
\hline Mean & 69.603 & 10.460 & 5.202 & 12.142 & 74.677 & 8.457 \\
Median & 44.976 & 9.862 & 5.055 & 12.000 & 67.700 & 7.729 \\
Maximum & 206.595 & 32.557 & 15.780 & 21.300 & 153.670 & 19.784 \\
Minimum & 5.402 & -2.300 & -3.836 & 5.740 & 18.000 & 5.065 \\
Std. Dev. & 62.303 & 6.472 & 2.466 & 3.508 & 40.693 & 2.716 \\
Skewnes & 0.806 & 0.716 & 0.217 & 0.199 & 0.234 & 1.846 \\
Kurtosis & 2.184 & 3.444 & 5.999 & 2.221 & 1.689 & 7.557 \\
JB-Stat & 62.019 & 42.813 & 174.572 & 14.543 & 36.790 & 653.632 \\
Obs & 456 & 456 & 456 & 456 & 456 & 456 \\
\hline
\end{tabular}

Table A3.

Simple Correlation Matrix (Full Sample)

\begin{tabular}{lccccc}
\hline Variable & CPI & FB & GDP & TBILL & EXR \\
\hline CPI & 1 & & & & \\
FB & -0.5780 & 1 & & & \\
GDP & 0.0890 & 0.0637 & 1 & & \\
TBILL & -0.5349 & 0.2359 & -0.2128 & 1 & \\
EXR & 0.9518 & -0.6238 & 0.0429 & -0.4987 & 1 \\
\hline
\end{tabular}

